\title{
Power, Legitimacy, and Urgency of Community-Based Tourism Stakeholders in Northeastern Thailand
}

\author{
Mattara Sripun ${ }^{1}$, Sekson Yongvanit ${ }^{1} \&$ Richard Pratt ${ }^{2}$ \\ ${ }^{1}$ Faculty of Humanities and Social Sciences, Khon Kaen University, Khon Kaen, Thailand \\ ${ }^{2}$ College of Social Sciences, University of Hawaii at Manoa, Honolulu, USA \\ Correspondence: Mattara Sripun, Development Science Program, Faculty of Humanities and Social Sciences, \\ Khon Kaen University, Khon Kaen, 40002, Thailand. E-mail: msripun@googlemail.com
}

Received: January 23, 2017

Accepted: February 6, 2017

Online Published: March 24, 2017

doi:10.5539/ass.v13n4p104

URL: https://doi.org/10.5539/ass.v13n4p104

\begin{abstract}
This paper examines the dynamics of Community-Based Tourism (CBT) stakeholder salience namely; power, legitimacy and urgency. Data is drawn from a doctoral research fieldwork, undertaken from 2013-2016 in two long running CBT villages in Northeastern Thailand which are Ban Prasat; an archaeological site in Nakhon Ratchasima province, and the ethnic Phu Tai cultural village of Ban Khok Kong in Kalasin province. Instruments include secondary data, participatory and non-participatory observations, and in-depth interviews using semi-structured questions with 53 key informants selected from 5 pre-defined stakeholder groups. Content analysis is employed using a modified stakeholder salience framework. The paper is structured into four main parts; an introduction to the theoretical foundations of the research, the examination of "legitimate" stakeholder groups and their dynamic relations, the discussion of stakeholder salience's fundamental concepts of "who and what really matters", and the limitations of applying a stakeholder approach in the CBT context. Findings unfold subtle but complex layers of process dynamics and stakeholder relationship. Women and the elderly are the backbone of a CBT process. Stakeholders play various roles based on group member skills. Roles and responsibilities are contingent, inclusive, and non-hierarchical. Functional differentiation serves as a management parameter and determines stakeholder urgency. Though CBT is managed through a participatory decision making process, the leaders are the most powerful stakeholder groups controlling tourism resources and regulations. CBT stakes are collective benefits. Normative legitimacy is found to be the most critical aspect. Interest overlap and the dynamic range of the stakeholder interrelations found in both CBT communities are too contingent and transitory for a unified thought on CBT management. Stakeholder interrelations transit as the setting evolves and the stakeholders themselves make decisions or change their opinions. This subjective element highlights moral essentiality and leadership dependence. Legitimacy is inevitably another form of power.
\end{abstract}

Keywords: Community-Based Tourism (CBT) stakeholders, Stakeholder Salience, Stakeholder Relations, Northeastern Thailand

\section{Introduction}

Current practices of tourist operation highlight a commitment to sustainability challenge, particularly on a local scale. Most tourism resources are based here and tourism is, to a great extent, recognized for its socio-economic and environmental benefits as well as its possible adverse consequences to the host communities (Ruiz-Ballesteros, 2011; Lacher \& Nepal, 2010). This is particularly apparent and significant in the Community-Based Tourism (CBT) approach that is increasingly seen as a potential contributor to the local economy and is a means by which sustainable tourism development can be achieved (Telfer \& Sharpley, 2008). Through the notion of community ownership, self regulation and community-based management, CBT intends to help empower local people to play a pro-active role in the tourism process and receive a fair and equitable share of the benefits from tourism (The Community Based Tourism Institute (CBT-I)).

The debate over tourism's impacts on the community still exists. Tourism management at the community level is widely acknowledged for its political implications. Communities are not homogenous and the interests of community members do not always coincide (Hall, 2007). This means managing the sometimes competing demands of tourism activities, social and cultural values, and resources used for tourism. Politics is ever present 
in the clash of different interests. This may include economic purpose, conservation, and protection of tradition, culture and heritage, environment as well as scale of development, pace and so on. Not all community members embrace tourism development or benefit equally from their participation in tourism. Tourism development tends to face pressures from outside investors. Communities with weak governance systems and lax internal control mechanisms that determine the degree to which a community can control its tourism process are likely to open up to large-scale development and go beyond the community's carrying capacity. This will inevitably bring major changes to the place that may cause great concern and lead to deterioration of the environment and eventually, displacement of the local residents (Murphy, 2005; Lortanavanit, 2009).

While the key concept of community involvement in the process is clearly important and essential for sustainable tourism development, there is a certain level that is only rhetoric in this approach. It is less apparent whether the development is truly driven by community interests, rather than such other factors as bias within the system, leadership, or corruption (Jeffries, 2001; Hall, 2007; Lortanavanit, 2009). There is also a certain degree of ambiguity as to whose interests within the community should be at the forefront of tourism plans. Uneven distribution of benefits is well documented in studies into tourism and local communities (Cole \& Morgan, 2010). Disproportionate benefits leads to tensions and conflicts within the community. Cases in which mainly elite groups benefit from tourism further underline the existing inequalities and differences in the community caused by mass tourism. However, in some successful cases of community-based tourism management, benefits from tourism, both tangible and intangible, can help solve conflicts, lessening tension and opposition to tourism development (Coria \& Calfucura, 2012). Communities differ in terms of the nature and scale of their tourism development. The importance of local management practices has not always been recognized in development planning (Bennett, Lemelin, Koster \& Budke, 2012). This has led to inappropriate development initiatives that provide only limited benefits to limited numbers of people and has put additional pressure on the resources.

\section{Theoretical Foundations of the Research}

This study applies the stakeholder salience framework proposed by Mitchell, Agle, \& Wood (1997) to examine the CBT management process through its stakeholder interactions. Mitchell, et al. derive a typology of stakeholders based on the attributes of power (the extent a party posses means to impose its will in a relationship), legitimacy (socially accepted and expected structures or behaviors), and urgency (time sensitivity or criticality of the stakeholder's claims). The stakeholders of community-based tourism are made up of different groups, and quite often, they have different purposes. Whilst it is not difficult to produce a list of stakeholders for an organization, identifying legitimate tourism stakeholders and determining their influences may not be an easy task as tourism is multi-faceted and one of the most complex and dynamic sectors.

Although the mainstream of literature in this area points to the role played by stakeholders in community-based tourism, a few previous studies have investigated the actual relationship between stakeholder involvement and the effectiveness of management practice; i.e. how and to what extent the practice has been fostered by their efforts or influenced by their relative power. To date, it is not always clear who are the "legitimate stakeholders and major beneficiaries" of tourism development within the community and which group of stakeholders the development objectives should satisfy the needs of. Moreover, it is also not easy to reconcile the requirements of these various stakeholders and their often contradictory interests. This consequently makes it extremely difficult to determine a well-balanced approach for the management of community-based tourism and its various stakeholders.

Drawing on an integrated approach through the descriptive and analytical lens of a stakeholder management framework, the study seeks to explore and make explicit, current practices in CBT management in Northeastern Thailand. Using the modified stakeholder salience framework, an examination is made of the identification of legitimate stakeholders, their salience, and the dynamics of stakeholder interrelations and interaction on CBT management processes.

\subsection{Defining and Interpreting Stakeholders Analytical Attributes in Community-Based Tourism}

A stakeholder approach to CBT is relative to the continuous process that results in the outcomes contributed by the various CBT stakeholders. Stakeholder components are highly interrelated because of the dynamic and multifunctional nature of the tourism process (see Figure 1). "Stake"-holders have a right to make demands which they perceive as important and urgent. Their demands are driven by their interests which are influenced by perceived benefits based on perceived values of CBT, both tangible; i.e. economic and physical means and intangible; i.e. quality, appropriateness, fitness for purpose or well-being. These stakeholder elements have different influences on the management process and each element plays a different role in different stages.

Legitimacy, in this context, is the belief that a person who has a "stake" in tourism in that particular territory has 
the right to make demands. Tourism stakeholder legitimacy is therefore, an acknowledgement of an interest to pursue community resources for tourism to gain its perceived benefits or avoid its potential costs and a general appreciation of this process to achieve desirable outcomes makes their actions highly legitimate. Legitimacy of stakeholders is contextual justice and fairness (Phillips, 2003). Stakeholder conflict over aims and outcomes of the tourism management process is often downplayed due to its complexity and highly political undertone, particularly the tourism that takes place where the governance structure is weak or informal (Hall, 2007). Collective actions in CBT management are only beneficial to those who are represented or included in the process. The successful outcomes of actions hence depend on the relative power of stakeholders and their success in co-managing resources to achieve a goal shared by all parties.

\section{Concept Mapping of Stakeholder Attributes in CBT}

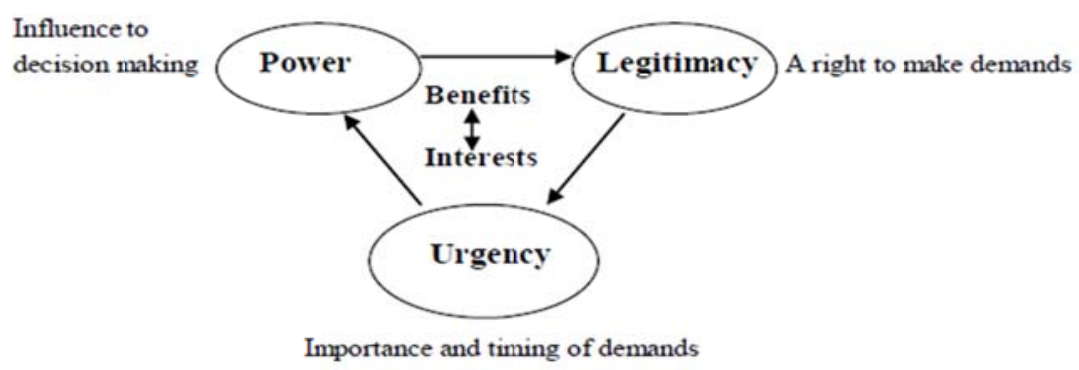

In Thailand, forms of collective action and social network have remained loosely structured, based on a horizontal relationship and consisting of largely independent affiliates (Lortanavanit, 2009). This means that social interactions among different groups of stakeholders can be undermined if stakeholders fall short of relative power in the control and management process. This modified stakeholder analytical framework encourages a multi-approach through systems thinking whereby all managerial components, including stakeholders and their involvement in the process as well as their impact on the system within the community, are incorporated. Different stakeholders may have different perspectives and needs or demands which should reflect the dynamics of the local context and practical elements.

\section{Research Methodology}

The study adopts a qualitative approach including such methods as in-depth interviews, participatory and non-participatory observations, and the use of related, existing studies. These qualitative methods are useful in different ways. Observations are effective in exploring the stakeholder group dynamics and allow the free flow of data collection on stakeholder normal behaviours in specified contexts, whilst in-depth interviews are useful in investigating stakeholder opinions and perceptions related to their CBT experiences.

\subsection{Scope of Population}

The population includes any CBT stakeholders in the selected study sites. Based on Freeman (1984) definition, "Stakeholder" is a group or individual who can affect or be affected by the achievement of the village's CBT management's objectives. Basically, any member of the village can be described as a "stakeholder". Stakeholders in this study fall into 5 groups: government officials, leaders, tourism entrepreneurs, community members, and tourists. The targeted population for the qualitative approach includes 53 key informants (10 Key informants from the group of leaders, elderly, local wisdom, head of local organizations and 43 representatives of stakeholder groups) from within the two selected communities (government officials, community leaders, tourism entrepreneurs, community members, and tourists).

\subsection{Selected Areas of Study}

\section{- Ban Prasat, NonSung District, Nakhon Ratchasima Province}

Ban Prasat is an archaeological site village chosen on the basis of the length of its tourism development which spans over 30 years, its social recognition as a CBT award-winning village, which has been widely acknowledged by the local network, and the village's tourism practices that highlight major premises of a sound CBT approach.

- Ban Phu Thai Khok Kong, KuchiNarai District, Kalasin Province 
Ban Phu Thai Khok Kong is another well-established and award-winning cultural tourism village of the Phu Thai ethnic group in the Northeast region that has been practicing CBT for nearly 20 years. Another important criterion for selecting this village as a study area is that it shares natural resources for tourism with the management of Nam Tok Tad Sung Forest Park. This element allows comparisons to be made between the two selected areas of study in terms of the different process components in managing CBT by different stakeholder groups.

\subsection{Methods and Data Collection}

The initial task involves conducting a secondary research to collect all related information, followed by making a number of field visits to get into the exploration of the surrounding context and gain a historical overview of change in the village, particularly in relation to tourism and its development within the community and arrange formal or informal one-on-one meetings with representatives of the individual stakeholder groups. This is necessary both to gain community history from key informants who possess knowledge about tourism development within their community and also because some of the information i.e. opinions about other stakeholders which is likely to be confidential. Following the introductory step and the identification of stakeholder groups, key informants from each of the indentified groups are selected for in-depth interviews. Each interview takes about an hour. The interviews are held in order to explore stakeholders' interests, needs, visions and the relative power of different stakeholder groups and their collaborative efforts in managing CBT.

Different strategies are used to identify key informants. The main strategy, with the assistance of the village headman and by asking community members through informal talks, is to cross-check the accuracy of the list of people who are involved with CBT management (preliminarily identified from existing studies according to research scope and approach). However, the selection of key informants for in-depth interviews is according to relevance and availability. A series of preliminarily visits to both study sites prior to the actual fieldwork are made to get a visual image of the village and "feel" a sense of the place as well as the dynamics of the people within the community. Participant observation is incorporated at the very beginning in order to not only understand the local context and key issues relating to research questions, but also to blend in with the lives of the people in the village. This method allows the formulation of firsthand accounts and fresh insights. The researcher is based in the study villages throughout the fieldwork.

The process of triangulation comprises of data multi-checking from different sources and different data collection methods. Thematic and content analysis is employed to analyze the data. It is an inductive process to find commonalities and differences in the data that lead to a description where an explanation, both inside and outside the study scope, can be checked and modified and a data organization which reads, summaries and codes to organize data into categories, sub-categories and theme generations, based on the research framework.

\section{Research Findings and Discussions}

\subsection{Identification of "Legitimate" Stakeholder Groups and Their Relations}

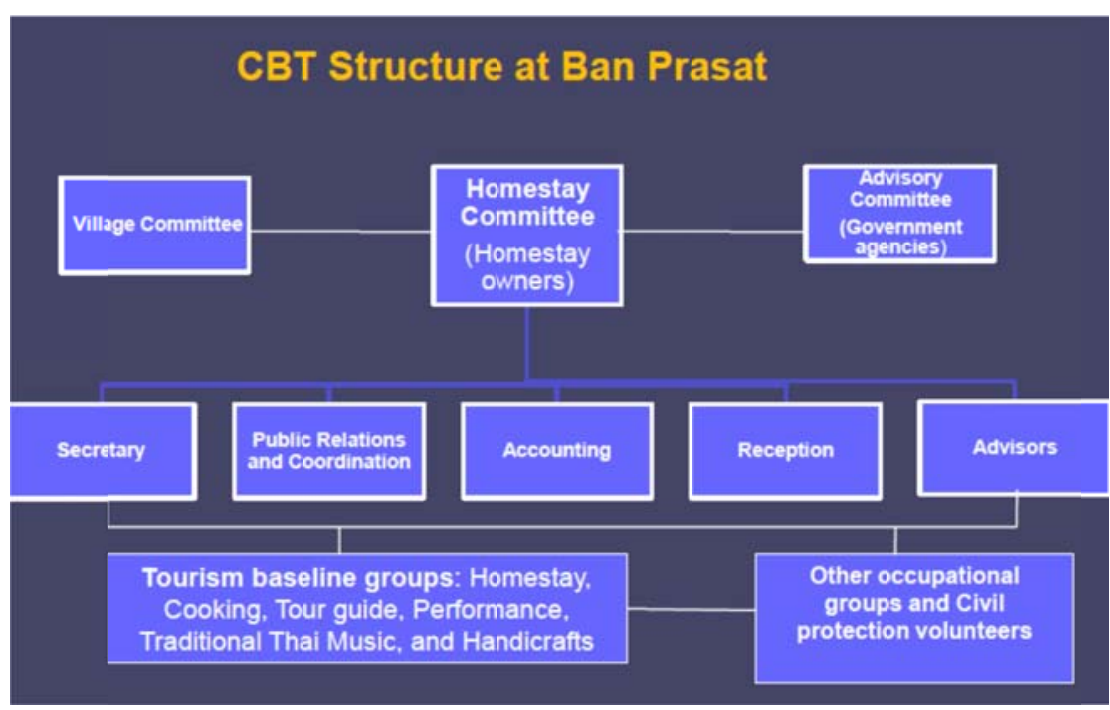

Figure 2. CBT structure at Ban Prasat

The structure of local organization at both villages mirrors that of the Thai village model; the village is governed by the village headman, elected by villagers, and the village committee, made up of prominent figures 
representing every segment in the village. Tourism is one of the village production groups entirely run by the villagers. Conceptually, all the group members are primary stakeholders as they "can directly affect or are affected by the achievement of the group objectives" and therefore they all have a legitimate interest in tourism and its "assumed" benefits. To include all of them as an inclusive community stakeholder, though, is difficult to accomplish. In practice, some stakeholders are more involved than others. A starting point, therefore, is to identify which stakeholder groups are and are not actively participating in the tourism process. The two villages organize their community tourism using different structures.

Tourism at Ban Prasat (see Figure 2) is operated and managed by the village homestay group committee of 19 members elected from the 23 members of the group (who are the homestay owners). The key role of the committee is to administer and manage all tourism related-activities. The committee is headed by the village headman and his deputy. The board is divided into 5 administrative units: 1) secretary, 2) public relations and coordination, 3) accounting, 4) reception, and 5) advisors. Although the committee advisors have no formal decision-making power, they are in practice a key driver in providing and shaping the direction of the work and administration of the group.

The homestay committee further incorporates other production (occupational) groups in the tourism plan and its implementation; the homestay group is an administrative centre while the occupational groups are operational units. The incorporated groups are mainly smaller tourism groups or occupational groups which can function independently or in association with the homestay group. These groups are: 1) cooking (foods and deserts), 2) local handicraft, 3) silk weaving, 4) traditional Thai music, 5) youth tour guide, 6) Palm-chair making, and 6) hat weaving. The village also has an advisory tourism committee (government agencies) to lend support and assistance: 1) District chief, 2) Director of the provincial Tourism Authority of Thailand (TAT), 3) Director of the provincial Fine Arts department, 4) Head of Tambon Administrative Organization (TAO), and 5) Director of the Ban Prasat School.

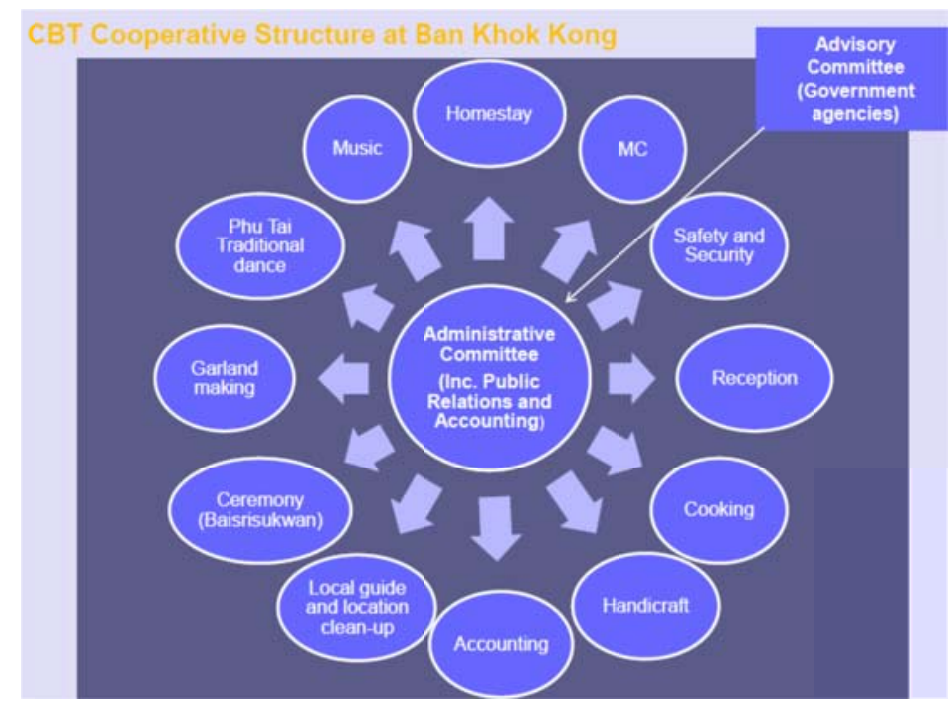

Figure 3. CBT cooperative structures at Ban Khok Kong

Ban Khok Kong tourism (see Figure 3) is organized in cooperative structures. The village tourism cooperative has operated under 13 committees consisting of: 1) administration (including public relations and accounting), 2) homestay, 3) master of ceremony, 4) safety and security, 5) reception, 6) cooking, 7) handicrafts, 8) accounting, 9) guide and location clean-up, 10) ceremony (baisrisukwan), 11) garland making, 12) Phu Tai traditional dance music, and 13) advisory committee. The composition of the Ban Khok Kong advisory committee reflects a strong local government tie. It includes people from various public sectors: District chief, Head of the local police, District development official, District culture official, Tambon development official, District chief, Mayor, Head of TAO, Director of Ban Khok Kong School, Director of Ban Nakri School, the Director, and Deputy of provincial tourism, sports, and recreation centre.

The tourism operation is controlled by the administrative group which is made up of the village leaders who are also members of the village committee. The tourism group members are simply divided into sub-groups based on the type of activities and most are headed by a member of the administrative committee (a member of the leader group). The cooperative members are free to choose any group they want to participate in. Apparently, some sub-groups are skill-based i.e. handicrafts, music and Phu Tai dance. Some are obviously gender-orientated, 
where all or almost all members of the group are either male or female i.e. the tasks of reception, cooking, garland making, Phu Tai traditional dance, are performed by women; while the music, safety and security, guide and location clean-up groups are made up of male members. The homestay and accounting groups are practically a branch administrative unit as all the members of these two groups are the same as those listed in the administrative committee. In reality, through a number of field observations, the task segmentation in Ban Khok Kong is very fluid. It is a simple division of labour, loosely applied to aid group operations and management. Tourism is a simple organization based upon primitive group units where group leaders take the lead in major community functions.

Community multilayered participation at Ban Prasat appears to be more orderly. Ban Prasat reflects a similarity in terms of sub-group organisation based upon task specialisation. However, such groups are not administratively and economically tied to the tourism group. The operational loop of tourism, therefore, is a lot smaller, with tighter control over the whole process. The homestay group is practically a single administrative unit made up of the community leaders. Only members of the homestay group are included. Rules and regulations of the homestay practice define the legitimacy of the interest and conduct. This approach draws the boundary of CBT practice and determines the scope of each group of the community primary stakeholders and their position in the tourism process.

Tourism sub-groups, which are mostly skill-based, in both villages are contingent, particularly handicrafts. It largely depends on member's skills and availability, market demand and trend, the volume of tourists in the village, and other development programs (i.e. One Tambon One Product (OTOP) promotional theme). The permanent groups are those that form the baseline services for tourist consumption including the homestay, cooking, tour guide, performance, music, and weaving crafts groups. Other small local enterprises and individual producers, in both villages, operate in a wider context. They not only serve tourism but the whole community. Shop owners (both private and communal), hair dressers, masseurs, motorbike service providers, and food vendors are present among this group.

\subsection{Defining Legitimate CBT Stakeholders: Primary and Secondary Stakeholders}

Setting against the nature of tourism stakeholders discussed in section 4.1, the legitimate CBT stakeholders can be characterized into two distinctive groups:

1) The key stakeholder who is an "actor/collaborator", falling into 4 sub-groups:

(1) Tourism leaders and group members of both the main and sub-groups.

(2) Tourism entrepreneurs-shop owners (both private and communal), hair dressers, masseurs, motorbike service providers, food vendors (food and drink), laundry service.

(3) Village members - audiences and extras

(4) Tourists - actors on the demand side

2) The supporting stakeholder who is the "facilitator/mentor" which falls into 3 sub-groups:

(1) Village leaders - village head (by position), former village head, teacher, village committee, representatives of village organizations (health volunteers, civic protection volunteers, village police volunteers, elderly protection volunteers, women's development group, village fund committee), village representatives in TAO.

(2) Government officials - advisory board and local non-committee government agencies.

(3) External tourism agencies - tour operators both local and national, Tourism Department officials, educational and training institutions, and the media.

\subsection{Stakeholder Collaborative Patterns}

CBT stakeholder collaborative patterns are a multi-layered process. Stakeholders take various roles, as parts of a formed group, based on member skills. Stakeholders perform different functions at different times during the tourism process. Roles and responsibilities are sometimes allocated on a temporary and contingent basis, according to inclusive and non-hierarchical relationships. All stakeholders are interdependent and inclusive with the various issues at stake based on their functional differentiation. Leaders direct and enable the group to achieve its objectives. Strong leadership is well documented in both case studies.

Functional elements of the group involve lots of meetings. From observing a number of community meetings during the field study, members are very engaged and they do not shy away from voicing their opinions or raising issues. They are very skilled at getting their views across and communicating with each other. Creativity 
and problem solving skills though are obviously provided by the leader group. Seniority is seen to exert a strong influence on others, in both communities. It can be described as a collaborative, dynamic process that is fuelled by a democratic act.

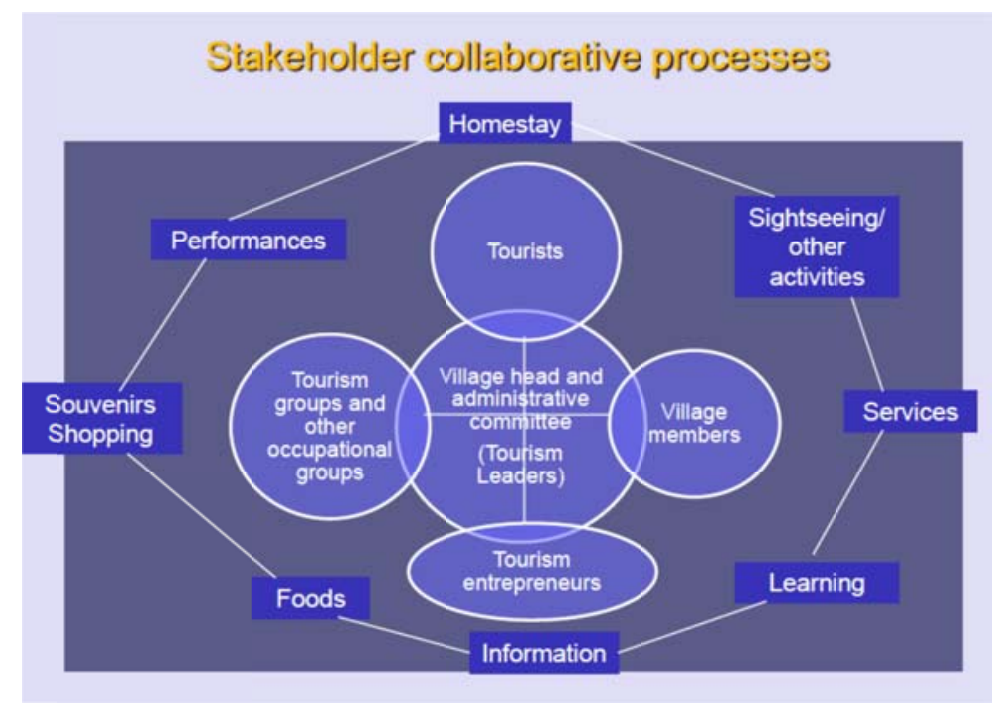

Figure 4. Stakeholder collaborative processes

Group relations are ancestrally tied. Members are neighbours, friends, relatives, or family. They share the same livelihood landscape, working together on their farms. Labour exchange is still practiced in both villages. Group members have various opportunities to discuss planned activities, talking things through with possible issues to be discussed. When there are "autocratic hiccups", they can be easily smoothed over through their informal conversations, for example, while working together on the farm or at the numerous social gatherings within their community i.e. at the temple, weddings, house warming ceremony or "Ngan Pattana" or community development events (mostly physical). These things are of minor importance i.e. designing menus for tourists, how much money should be spent on cooking ingredients, who should be doing the shopping, which performances should be put on, or whose crafts are better for the market. They might get annoyed but in the end, they work together anyway. Seniority plays a significant part in smoothing over hiccups. From a direct observation, everyone in the village is linked to others (one or another); they share a daily life boundary (next door to one another at home or at the farm). Their level of tolerance is emblematic of a more embedded tribal value; that they share ancestral ties.

\subsection{Characteristics of Stakeholder Salience and Its Fundamental Concepts of "Who and What Really Matters"}

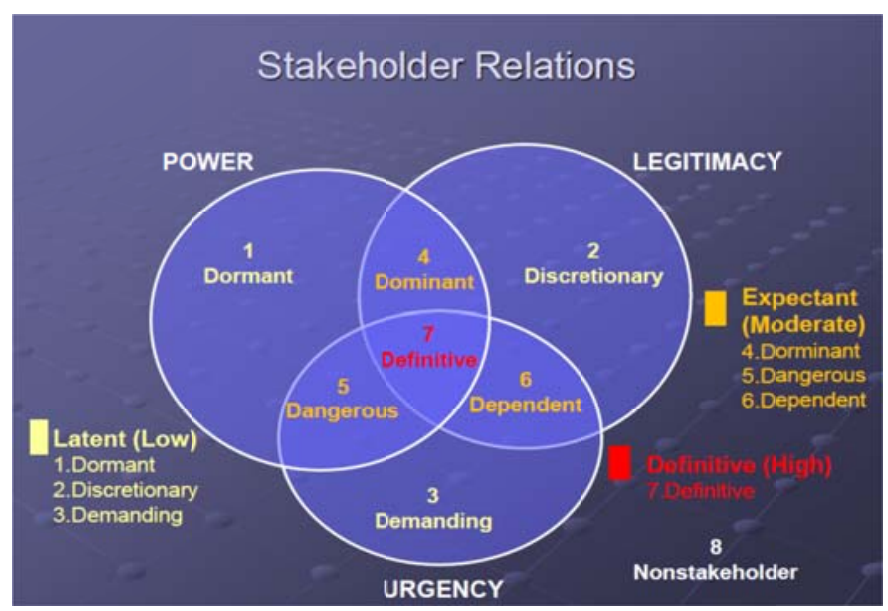

Figure 5. Stakeholder analytical framework adapted from Mitchell et.al., 1997 p.874

\subsubsection{Power: Types of Relative Power, How It has Been Exercised, and Its Influence on the CBT Process}

Mitchell, et al. (1997) defines power as "the extent a party has means to impose its will in a relationship". This research modified and operationalised the concept of relative power as a possession of means to exercise such 
power and influence the tourism processes and stakeholder relationship. A set of CBT relative powers over the CBT management process can be categorised as follows:

1) Formal power: Means of this power include the right to acquire the action of others by being in an officially appointed position. It is an official power. CBT stakeholders who possess this type of power include the village head, village committee, village volunteers in appointed groups, government officials related to tourism activities (TAO, development officials, and Provincial Tourism authority). It is common to refer to "formal power" as authority. It is the official right to act, based on position. Authority is one source of power, but people in authority are not always powerful. Authorities in both CBT villages include village head and village committee. CBT power is formed by the local governance structure. The village head serves as a government body who acts as a medium in regulating people and resources for tourism. The village self -regulating system is still under state influence. Leaders, in this perspective, are a form of dominance. In both CBT communities, village head is the most powerful person in the CBT processes. It is a right that cannot be opposed as the village head is elected by village members. Any opposition they may have can be settled by the acknowledgement of the position. There is no opposition once the election is over. However, such opposition (naturally from those who did not elect/not support the person/the opponents) is to be played out /influence their will to participate/ and level of their efforts to put forward CBT activities being led by the leader who is their opponent.

The CBT dynamic in both villages is clearly a political process with the subtle complexity of social relations and interactions, influenced by culture. This is particularly the case of Ban Khok Kong as the length of their CBT has spanned over the administration of three village heads. The bigger the size of their support, the higher the influence they have on group decision making and also the degree of participation as well as the efficiency of the tasks being done. For instance, the community members may have been divided 70:30. Seventy percent of them support the current administration, while the rest, 30 percent, support the former leader. This 30 percent of the community members accept the election result but are not necessarily enthusiastic about village social activities. Nevertheless, villagers are largely related to each other by blood (partly as a result of intra-ethnic marriage in older generations); in some households, the husband is a relative of the former leader while the wife is a relative of the current one or vice versa. Therefore, they are not strongly opposed to one another. It is more of a compromise situation. CBT, at the ethnic village of Ban Khok Kong, is a very clear example of a family (social) enterprise; they are just one big family and they compromise because it is a family affair. CBT at Ban Prasat has only been led by two village chiefs and the current village headman is the successor of the former leader (his assistant and also nephew) who is a strong supporter and carries on leading in the background.

2) Normative power: This is related to norms of behaviour or a general acceptance of an individual in a community. Spiritual, respected figures and informal leaders of the community belong to this group. This group is the backbone of CBT force in both villages. The elders, local wisdoms, former village heads, CBT creators are held in the highest regard, their opinions mean a great deal and are advocated with high priority. This group has a strong impact on group decision making. Their interests/visions/agendas influence the whole process. They are the main support and a major sustaining factor of the CBT practice in both communities. Their presence is strongly influential. Seniority is a source of power. Thai society is still hierarchical; seniors (both men and women) continue to be treated with respect. The CBT seniors are mostly found in the group of informal leaders i.e. well respected elders, local wisdom, and spiritual figures.

3) Utilitarian power: This is a power based on the possession of resources including materials, skills, and knowledge. A teacher is among this group at both villages. CBT relies heavily on their resourceful power. Others are those with materials i.e. nice houses to be homestays and funding for improvement or investment in new tourism ventures. In Ban Prasat this includes the Fine Arts department that operates the museum. And Ban Khok Kong is a Forest park that has full control over the park utilisation as a tourist attraction.

\subsubsection{Legitimacy: Types of Stakeholder Rights (Contextually Judged) and Putting Them in Practice}

The context of legitimacy in this research is a generalised perception that the conduct of a participant is desirable or appropriate in accordance with a socially constructed context that may be individual, communal, or social. Anyone who has a "stake" in tourism, in that particular territory, has the right to make demands and can be described as a stakeholder. However, to be productively legitimized or socially accepted in their right or claim for a stake, the stakeholder has to act upon their legitimacy. Basically, all community stakeholders have a right to participate in tourism activities. Forms of legitimacy found in this study can be categorised in three access channels; voice, rights and participation. Villagers can voice their opinions on tourism matters. But their opinion will not have as strong an impact as of those who are tourism group members or leaders. The more actively involved the stakeholders are, the higher the legitimacy of the claims of their demands/shared benefits. In 
practice, certain stakeholders participate while others do not. The levels of stakeholder participation also vary. Both communities have their own regulating system to manage variation and ensure contextual justice and fairness in the CBT process. The village head has full legitimacy to CBT claims by position and the inclusiveness of his/her participation in the process. Tourism groups have the right to benefits based on their functions. Profit distribution is clearly defined in the rules and regulations, and so are roles and responsibilities.

Power alone is not enough to determine stakeholders' influence. It requires legitimacy to exercise the power. It is clear why it is important for a person or a group to have legitimacy; it means they can participate and affect CBT processes. However, the main argument is about whom or what confers legitimacy on a person or group; who influences or has the final say in making decisions which are assumed to be egalitarian. The particular 'who' or 'what' that confers legitimacy is inevitably another source of power. This underlines the inherent limitations of the stakeholder salience concepts. In these two villages, decisions are always made by voting and consensus but embedded culture and values, where mentality is framed by cultural factors, for example, respecting the seniors, caring about what others think, or not being able to be upfront, somehow influence the villager's democratic self. It is allegedly the Thai style of democracy. In both case studies, forms of their collective action and local governance are still loosely structured and largely based on the trust and strength of their social relations. Interactions among different groups of stakeholders and process outcomes can be undermined if stakeholders lack relative power over the control and management process. This is perhaps one impediment to a normative legitimacy; it places too much faith on morality and quality of leadership in which both attributes are highly subjective and difficult to control and manage.

\subsubsection{Urgency: The Type of Stakeholder Demand or Related Issues that Stakeholders Have}

There are two dimensions of stakeholder demands; the importance of the claim or the relationship to the stakeholders and the urgency of demands that calls for immediate action. Demands can be freely expressed by all stakeholders but the importance and urgency of demands are determined by the tourism committee. However, the decision over any actions or implementations resulting from such demands is made through a managed participation process. Unequal power is well observed during the process. In both communities, power is strongly associated to a group of CBT creators/founders with a decisive leadership. Demands can be categorized into 4 groups: 1) personal, 2) situational, 3) operational, and 4) organizational. Issues that generate the demands of villagers revolve around their daily life. It is all about community characteristics. Government officials are more concerned with organizational issues; tourism and other development plans and implementations, funding and resource allocation, for example.

\subsubsection{Description of Each Stakeholder Type}

Stakeholders fall into seven different types within three main groups, which are interrelated and can be overlapped. From the analytical salience model exhibited in Figure 5, the more attributes (power, legitimacy, and urgency) a stakeholder is perceived to have, the greater their influence, and priority.

Latent Group - These stakeholder groups have only one attribute. Sometimes, they may not be recognized as their salience, though, existing is not yet developed or manifested. Stakeholders need to acknowledge their relative power and have a will to execute it.

1) Dormant Stakeholders - These are CBT stakeholders with potential. They possess means to exercise their power but have little or no interaction or involvement because they do not have legitimacy or urgency. Participation and action of this group will legitimize their position in the group activities and their demands will receive a great deal of priority given their relative power. CBT stakeholders in this category include inactive resourceful persons, officials of the forest park and the museum, district officials who are local policy makers, local investors, CBT associations, tourism agencies and organizations, educational institutions, local NGOs, media, future generations, and future returning migrants.

2) Discretionary Stakeholders- These stakeholders are basically village residents who have little or no interaction or involvement because they do not have power or urgency. Empowerment of this group is needed to reinforce their participation and involvement with CBT activities.

3) Demanding Stakeholders - They are people with urgent demands, but no legitimacy or power. Conventional and non-return tourists and provincial authorities are among stakeholders from this group.

Expectant Group - Stakeholders in the expectant group have two attributes. They are active CBT group members with expectations (for perceived benefits).

4) Dominant Stakeholders - This is an influencing and powerful group that drives the community to achieve its CBT goals. Community leaders and the women-based CBT groups fall into this stakeholder type. 
5) Dangerous Stakeholders - Those with power and urgent claims will be coercive to ensure their demands are being met. This type of stakeholder is considerably irregular, and context-bound; demanding public authorities during a festive event or official visit, for instance. This group is conceptually a threat to an organization or a group that makes decisions. However, in the CBT context, this threat is regarding the shared sense that they are a community and how they want to open up to tourism development (scale). It indicates their perceived level of control over the CBT operation. If a large sum of benefits are at stake, quite often the community with weak internal controls will gradually open up and bring in more investment (mostly from outsiders) and it reaches a point where the nature of the CBT is shifting away from the left of the continuum (owned, controlled and managed by the community) to the right, where tourism stakes are largely held by outsiders.

6) Dependent Stakeholders - Stakeholders who are dependent on others to carry out their will, because they lack the power to claim their stake. For example, local residents who want to participate with tourism activities but lack materials, skills or knowledge to fully take part. Their interests can be advocated by dominant stakeholders, and that potentially makes them definitive stakeholders.

Definitive Group - Stakeholders in this group have all three attributes. They are the actors whose demands call for immediate attention.

7) Definitive Stakeholders - These stakeholders are practically dominant stakeholders with an urgent issue, or dependent groups with powerful means such as a big sum of remittance. This is the most active, core group of the CBT; they are opinion leaders or the decision making group.

\subsection{Discussions}

The fundamental idea of the stakeholder approach to CBT management is to allow a thorough examination of all the functions of the CBT unit. Such explication provides a clear understanding of community structures and underlines external and internal factors affecting CBT functions and its stakeholders which interact in the course of CBT activities. The stakeholder salience model is highly dynamic. The interrelation of the three domains will change as the environment evolves and as the stakeholders themselves, make decisions or change their opinions. One type of stakeholder can become another, it depends on the type of their actions and the urgency of their demands. Given the case of dormant stakeholders, for example, each group of dormant stakeholders has a potential interest in CBT and also has potential sources of power and can make the most of their power by contributing to CBT processes. Their issues stand for priority, given the degree of their possible contribution. Ban Prasat weekly commuters or migrants who work away from the village are part of the community but they are not a primary stakeholder; they have a potential to influence the process but are neither directly engaged nor essential for the achievement of CBT purposes. They might earn enough money to start a small tourism related enterprise in the village; a coffee shop, for example. Unless they execute this potential, which is presumably driven by their time availability and socio-economic interests, they will not be making a transit to the definitive stakeholder domain.

This is not always the case, it could be vice versa; the dormant commuters might be interested in investing in tourism but they don't have skills or enough start-up funds, therefore they decline participation. In Ban Prasat, those whose houses are near the pits have no interest in investing in tourism enterprises, while the interested ones are located too far away from the spot. In this case, they do not belong to a dormant stakeholder type but the discretionary one because they do not have either power (capital, time, knowledge, or skills) or urgency (interest). Therefore, their legitimacy is optional and contingent. Conceptually, empowerment is needed to enable the participation of a discretionary group. The same as local government in Ban Khok Kong, for instance, the TAO could mobilize more of their development budget towards tourism activities or the infrastructure that supports it. Anyone who only voices their needs, but without power or legitimacy, can only be described as the demanding type. It depends on the community to weigh such demand and its possible impact on the CBT.

The most influential groups of both case studies are the group of leaders, local officials, and CBT groups (which form part of the occupational groups). They possess means to exercise their power and they take part with expected outcomes that can be described as perceived benefits. Any primary stakeholder has an agenda; it is only a matter of context variation of their agenda or interest as discussed in the previous section. The dominant stakeholders are very functional and their performances are very important for CBT survival. However some of them might fall short in some areas, such as entrepreneurial skills or insightful visions. Meanwhile, the dependent type comprises of those stakeholders who participate and have certain demands i.e. earning income from tourism activities but lack relative power i.e. they are not a member of any groups, can only take part as an extra when tourism activities take place in the village. A clear example of this group is the villagers at Ban Khok Kong whose task is to line up in a greeting row when tourists arrive. They might want to do more but they do not 
have skills or are not in a position that facilitates their will to be more involved. All attributes are very fluid and transitory. They can flow in all directions. Acknowledgement of each attribute is a matter of varying perceptions and is socially constructed in practice.

The explication of stakeholder salience analysis clearly unravels a complex relationship among CBT stakeholder groups, their existing power, and how their action or non-action, as well as the needs of each group, could impact tourism processes and outcomes. The core concept of stakeholder management is to give priority to those in possession of all three attributes. The problem with this analysis is that, though it explicates the layers of process dynamics and what the whole process entails (actors and their interactions), the dynamic range is too wide. The case of Ban Khok Kong gives a vivid account of such intricacies as it is a participation of the whole community. Leaders play several roles in this multi-layered stakeholder process. Some of them belong to more than one group. For instance, a TAO representative of Ban Khok Kong is a village committee member, part of a CBT leader group, and also a member of an occupational group as he and his spouse are homestay owners. The spouse's multi-roles in the CBT process further add more layers to the web of an overlap. She heads one of many CBT function groups (cooking) and is also part of the location as well as housewife groups, and in the meantime co-runs a homestay with her husband. Similar to Ban Prasat, the village headman is a village leader; he is also part of a homestay member group, a tour guide, while his spouse leads the cooking group and is part of the homestay owner group.

As discussed in the section of stakeholder collaborative patterns, CBT management, at both villages, is a multi-layered process of stakeholder relations and interactions. Functional differentiation is a parameter for their local management. Their inclusive and non-hierarchical relationship, temporary and contingent roles and responsibilities, make CBT stakeholders interdependent with each other while involving various issues at stake. This is a process that requires an effective teamwork and task routinisation under strong leadership in directing, controlling, managing, and maintaining the whole process. It is the segmentation of the self to accommodate different functions within the group; wearing different hats (where the hat is the role). Pluralism reflected in the multiple, overlapping CBT group membership is very important for the operation of democratic societies because it deconcentrates and diffuses power.

In a number of the conditions discussed so far, group labeling makes less sense to their action, though determined by functions, is subject to the individual and the social setting. It's clear that the multi-roles played by stakeholders, in both case studies, are a group of leading figures or the working group (Klum Khon Tam Ngan), who are in a powerful position to influence others and their decision making. The notion of co-managing actions and communal collaboration means that collective actions only benefit those who participate. In a business sense, including tourism in general, participation reflects a tendency towards self-interest with an individual or a firm focusing on returns of investment. Collective economic activity is always the challenge being posed by conflict of interests and profit share. Long-term benefits and a collective view tend to be undermined by desire for short-term gains. In other words, a community member should want to be in the domain of "definitive stakeholders" to make the most of the power and gain the upper hand in benefit negotiations. Yet, the nature of the CBT stakes they are holding, are mainly common stakes. It is a benefit for all, a collective community benefit, not for an individual. The challenge posed by it is, therefore, a community's ability to be fully charged and responsible of their collective interests as well as those of their own group.

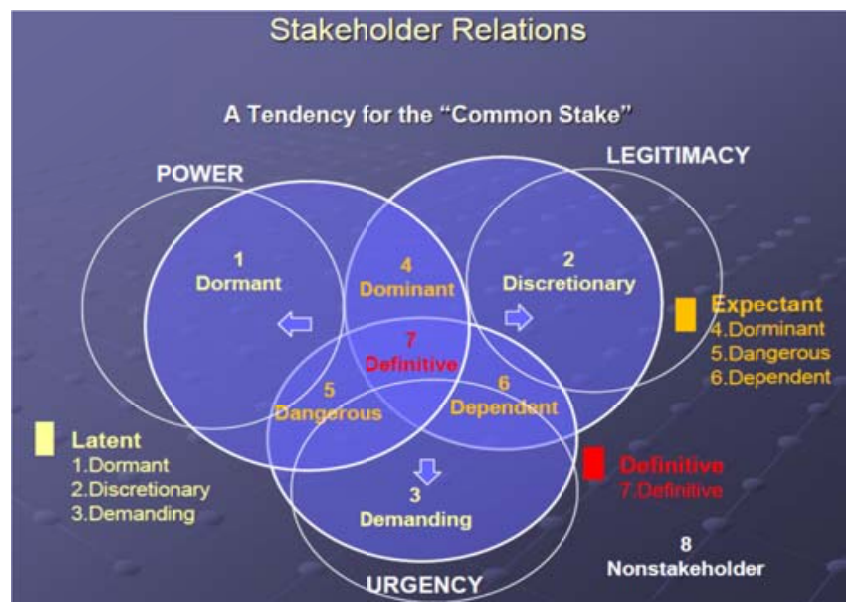

Figure 6. The dynamic relations of CBT stakeholders in diverse directions 
With reference to Hardin's Tragedy of the Commons reexamined twenty-two years later by Feeny et.al. (1990), these complex and subtle processes of the CBT, where stakes are collective benefits, share the two important characteristics of common-property resources. The first is excludability or the control of access. All community members are CBT stakeholders and entitled to take part in the process. The control of access by legitimate group members is against the core concept of CBT management. Moreover, both physical and cultural community resources typically pose obvious problems of exclusion; resources belong to everyone. The second characteristic of common-property resources is that they are subtractable. Each community stakeholder is capable of subtracting the welfare of others. They may co-deliver the productivity of their resources, for instance by group work, the nature of the CBT collective work is such that the level of action by one member can affect the ability of another member to gain from the resource. Subtractability (i.e. selfishness and the problem of free riders) is the varying degree between individual and collective judgment. If one member neglects group responsibilities, others will experience an increase in their work load and it might cost them their time and energy that could enhance their individual productivity. Instead of competing and negotiating for their claims of tourism benefits, the CBT stakeholders are, consciously or unconsciously, gravitating toward subtracting from the welfare of others in the community, or the inevitability of a free-rider problem found in both case studies. The dynamic relations of CBT stakeholders could be flown in diverse directions as exhibited in Figure 6. To be practiced in a fair and equitable manner, CBT faces the dilemma where exclusion is unethical and collective action involves subtractability. Ideally, discernment belongs to everyone but in practice, some stakeholders are more equal than others. Those who are dedicated to social work carry on doing so; it is a case of where there is a lot of population in the community, but only a few citizens. These shared characteristics of common aspects underpin the nature of the CBT found in the two case studies and the nature of those who confer its legitimacy.

\subsection{The Limitations of Applying a Stakeholder Approach in the CBT Context}

The stakeholder approach is people-centric; it projects people as a driver of management processes. By using this approach in a CBT study, it requires the identification of all involved in the process, their relative powers, and how that influences others and the management dynamics. Community characteristics involve a complex set of people with different interests, norms, characteristics, and culture. These elements are the main components of a community-based approach where tourism is owned, controlled, and managed by its people (stakeholders). The analytical stakeholder framework requires the unfolding of the intricacies of people's interests and interrelations in a structured way; and how the whole picture (people and their settings) might be understood.

The model is clearly useful in explaining stakeholder behavior, and identifying who are very important to the group and what issues are really important and worth pursuing. However, using the stakeholder approach in CBT refers back to the fundamental dilemma of the stakeholder approach regarding whose interests, which often are contradictory, within the community should be at the forefront of tourism plans. In practice, the core concept of stakeholder management "who and what really matters" is a mere rhetorical prose of "who and who really matters", by which demand determinants vary. CBT involves a complex set of multi-scaled stakeholders who impact on functions of tourism and the community at different levels. Interest overlap and the dynamic range of the stakeholder interrelations found in both CBT communities are too contingent and transitory for a unified thought on CBT management. Even operating within a specified group, and therefore deeming to collaborate in at least some aspects, stakeholders differ in; interests, skills, resources, and engagement. Authority often has the final say on approving, rejecting, or forcing proposed projects or activities. The findings are consistent with later work of Mitchell, Agle, Chrisman \& Spence (2011) on a theory of stakeholder salience in family firms. They argue that "where principal institutions intersect i.e. family and business, managerial perceptions of stakeholder salience will be different and more complex than those based on a single dominant logic".

\section{Conclusion}

The contribution from the community-based approach is the underlying power of the community leaders who have a total control over tourism resources and underpin the CBT processes; identify types of CBT leader powers and define community-based leadership. Given the common nature of CBT stakes, this study points out the significance of local leadership in community building and reinforcing citizen responsibility through CBT management processes. It indicates that a viable community-based management approach, which incorporates institutional arrangements and cultural factors, can potentially help by strengthening people's participation and citizen solidarity through community-based processes and collective leadership. All tourism stakeholders, who are implicated by tourism, can influence the scale and pace of tourism development and its management.

Communities may not benefit directly from this study but the message is very important for policy formulation and implementation in strengthening communities and their people through local democratic structures and 
social activities such as CBT. Sustainable tourism practices are all about local control and how the community manages to work together. It is a matter of how resources have been used, allocated, and governed by all community stakeholders. CBT is an educational process: it is both a mechanism and a process that trains and educates the community to be self-regulated and self-reliant in managing the web of their diversified livelihoods. Women's roles and impacts on the CBT processes are very important and should be continuously strengthened through capacity building initiatives. Experiences from the CBT local management in this study reaffirm the value and applicability of context-bound approaches to sustainable tourism development.

However, the application of organization-based concepts in community settings, where interests are not restricted to the specified objectives of such activities, is inherently problematic. Normative legitimacy is another form of power. Given the common nature of CBT stakes, the stakeholder framework accentuates leadership dependence and a demand for continuity of collective consciousness; a moral burden laid on the shoulders of all community "legitimate" stakeholders.

\section{References}

Bennett, N., Lemelin, R. H., Koster, R., \& Budke, I., (2012). A capital assets framework for appraising and building capacity for tourism development in aboriginal protected area gateway communities. Tourism Management, 33(4), 752-766. https://doi.org/10.1016/j.tourman.2011.08.009

Butler, R. W. (1980). The concept of a tourist area cycle of evolution: implications for management of resources. Canadian Geographer, 24, 5-12. https://doi.org/10.1111/j.1541-0064.1980.tb00970.x

Coria, J., \& Calfucura, E. (2012). Ecotourism and the development of indigenous communities: the good, the bad, and the ugly, Ecological Economics, 73, 47-55. https://doi.org/10.1016/j.ecolecon.2011.10.024

Cole, S., \& Morgan, N. (2010). Tourism and Inequality: Problems and Prospects. CAB international. https://doi.org/10.1079/9781845936624.0000

Feeny, D., Berkes, F., McCay, B., \& Acheson, J. M. (1990). The Tragedy of the Commons: Twenty-Two Years Later. Human Ecology, 18(1), 1-19. https://doi.org/10.1007/BF00889070

Freeman, R. E., (1984). Strategic Management- A Stakeholder Approach. MA, Boston: Pitman.

Hall, M. (2007). Tourism, Governance and the (mis-)location of Power. In A. Church, \& T. Coles (Eds.), Tourism Power and Space: Contemporary geographies of Leisure, Tourism and Mobility. Oxon, UK: Routledge

Jeffries, D. (2001). Governments and Tourism. Oxford, UK: Butterworth-Heinemann.

Lacher, R., \& Nepal, S. (2010). Dependency and Development in Northern Thailand. Annals of Tourism Research, 37(1), 947-968. https://doi.org/10.1016/j.annals.2010.03.005

Lortanavanit, D. (2009). Decentralization, Empowerment and Tourism Development: Pai Town in Mae Hong Son, Thailand. Southeast Asian Studies, 47(2).

Mathieson, A., \& Wall, G. (1995). Tourism: Economic, Physical \& Social Impact. Longman Group Limited.

Mitchell, R. K., Agle, B. R., \& Wood, D. J. (1997). Toward a Theory of Stakeholder Identification and Salience: Defining the Principle of Who and What Really Counts. Academy of Management Review (Academy of Management), 22(4), 853-886. https://doi.org/10.5465/AMR.1997.9711022105

Mitchell, R. K., Agle, B. R., Chrisman, J. J., \& Spence, L. J. (2011). Toward a Theory of Stakeholder Salience in Family Firms. Business Ethics Quarterly, 21(2), p. 235-255. https://doi.org/10.5840/beq201121215

Murphy, P. E. (2005). Tourism and Sustainable Development. In W. F. Theobald (Ed.), Global tourism: The next decade (3rd ed.), Oxford:Butterworth-Heinemann.

Phillips, R. (2003). Stakeholder Theory and Organizational Ethics. San Francisco: Berrett-Koehler Publishers.

Ruiz-Ballesteros, E. (2011). Social-Ecological and Community-Based Tourism: An approach from Agua Blanca, Ecuador. Tourism Management, 32, 655-666. https://doi.org/10.1016/j.tourman.2010.05.021

Telfer, D., \& Sharpley, R. (2008). Tourism and Development in the Developing World. Routledge Perspectives on Development, Oxon, UK: Routledge

\section{Copyrights}

Copyright for this article is retained by the author(s), with first publication rights granted to the journal.

This is an open-access article distributed under the terms and conditions of the Creative Commons Attribution

license (http://creativecommons.org/licenses/by/4.0/). 